\title{
Communication-Cognition 'Butterfly' (Geometrical Model of Verbal Communication in Case of Ambiguity)
}

\author{
Ilham A. Taghiyev \\ Department of the English Language and Literature \\ Khazar University \\ 41, Mahsati street, AZ 1096 \\ Baku, Azerbaijan
}

\begin{abstract}
The present paper deals with the traditional semantic triangle from the perspective of successful / unsuccessful communication in case of linguistic ambiguity and examines the limitations of the triangle in description of communication-cognition process. It is maintained that the semantic triangle merely explains the relationship between sign, concept and referent and describes how the received linguistic signs are decoded but fails to demonstrate the process of communication which is the main function of human language. An attempt is made to model and demonstrate communication-cognition process in case of linguistic ambiguity geometrically. Thus, instead of the semantic triangle, the author suggests a new geometrical shape dubbed "communication-cognition 'butterfly" which includes both the source and recipient of linguistic signs and is tested by means of English linguistic humor based on ambiguity.
\end{abstract}

Key words: semantic triangle, verbal communication, symbol theory, communication-cognition butterfly, ambiguity, linguistic hum

The use of the terms geometry and linguistics is not a mere juxtaposition as it may seem at first sight. The classical 'sign - concept - referent' triangle or so-called semantic triangle of 'expression - meaning - context' are well-known examples of it. Moreover, the so-called semantic map, being a geometrical representation of functions in "conceptual/semantic space" that are linked by connecting lines, (Martin Haspelmath. 2000) and the 'syntactic tree' that is widely used by structuralists can successfully exemplify the geometry of linguistics.

The above semantic triangle has been challenged and modified by scholars over the years. For example, semioticians such as Umberto Eco, thought that it was overly simplistic. For this reason, various scholars revised, modified it, or suggested their own alternative models of it. Today, in linguistic literature, we can encounter different triangles with different names of their vertices. Thus, the most common of them are:

Left vertex - Sign; Symbol; Term; Expression; Representation, Right vertex - Referent; Object; Phenomenon, Top vertex - Concept; Thought; Knowledge; Reference; Meaning.

In this regard, Sue Ellen Wright maintains that "One of the major deterrents to using the triangle is its numerous interpretations and the variable of terminology associated with the nodes of the triangle." (Sue Ellen Wright, Google Books) The case is, the difference between the triangles is not only in the names of their vertices, but also in the geometrical location of these names. Besides, the triangle itself has various names such as the Semantic Triangle, the Semiotic Triangle, the Referent Triangle, the Ogden-Richards Triangle etc. To avoid confusion, and for ad

hoc purpose, we will name the triangle we are dealing with the classical "sign-concept-referent" triangle. By sign we mean linguistic sign, i.e. spoken or written words and expressions that stand for the referent. By referent we mean not only objects, but also prior linguistic experience. By concept we mean mental image or thought which in its turn refers to the referent. Besides, the following abbreviations are used in the paper: $\mathrm{S}$ - sign, SR - sender's referent, RR recipient's referent, $\mathrm{SC}$ - sender's concept, $\mathrm{RC}$ - recipient's concept.

\section{Literature Review}

Charles Ogden and Ivor Richards, in their very intriguing to my opinion book entitled "The Meaning of Meaning: A Study of the Influence of Language upon Thought and the Science of Symbolism" (1923), claim that understanding comes from within the people rather than from the words they just interpret. Explaining the semantic triangle, they maintain that words do not mean; people mean. 
In their above-mentioned book they presented three theories, viz the Meaning Theory, the Symbol Theory and the Definition Theory. These theories viz the Meaning Theory, the Symbol Theory and the Definition Theory deserve to be focused on as they serve the purpose of the present paper.

According to their Meaning Theory, there is not a single "correct" meaning associated with each and every word because each word means something different to each person. According to the Symbol Theory, words evoke images and personal meaning is based on experience. According to the Definition Theory, in order to avoid this ambiguity we need to define terms and concepts. (ibid)

In Ogden and Richards' original semiotic triangle, the left vertex is named Symbol, the top vertex is named Thought or Reference and the right vertex is named Referent:

\section{Thought or Reference}

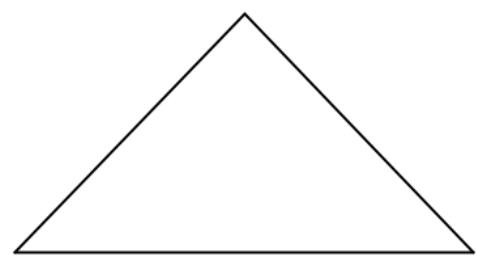

Symbol Referent

Fig. - 1 The original semiotic triangle (Ogden \& Richards, 1923)

According to the Oxford Dictionary, the 500 most used words in the English language have an average 28 meanings per word. That is why when people attempt to communicate through the use of arbitrary words, sometimes the communication breaks because of misconceptions and ambiguity. Words have no exact or clear meaning and meaning depends not only on the context, but also on the recipient of the arbitrary linguistic signs and his experience. One more triangle was suggested by Edward Finegan. Describing three faces of language, he writes: "Besides meaning and expression, then, there is a third aspect to language, and it is the context in which expression and meaning are linked. As represented in the triangle below, language is better viewed as a three-sided figure: expression, meaning and context." (Finegan, 2008-7)

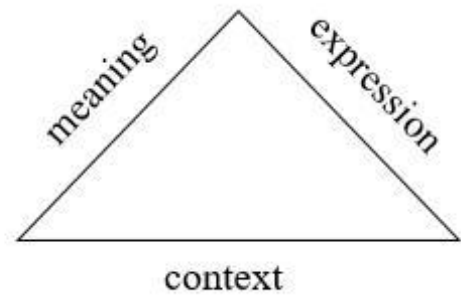

Fig. 2 Expression-meaning-context triangle (Finegan, 2008)

According to Halliday, language is a "meaning potential" and linguistics is the study of "how people exchange meaning by "languaging" (Halliday, 1985 -193). Thus, in the process of verbal communication, people exchange meaning by using linguistic signs, i.e. words and expressions. As linguistic signs are arbitrary, then, human communication takes place between two minds indirectly, i.e. through linguistic signs that evoke concept or meaning in people's minds. Then, meaning is something subjective rather than objective and cannot exist beyond people's minds.

\section{Discussion}

No matter how the vertices of these triangles are dubbed, all of them imply that upon receiving a sign (left vertex of the triangle), the person connects it to the referent (right vertex of the triangle) and has its mental image or concept of the representation of the sign (top vertex of the triangle) in his mind. That is why, we prefer the classical "Sign-ConceptReferent" triangle and further we will refer to it. 


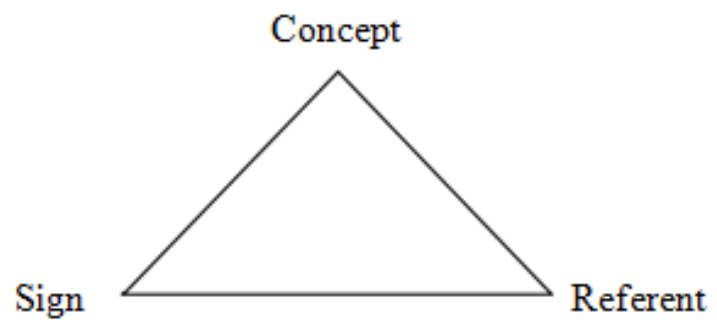

Fig. -3 The classical sign-concept-referent triangle

The above triangle is also represented by some researchers as a triangular pyramid (tetrahedron) with the fourth vertex on its base named 'definition'. (e.g. Suonuuti). In this case, the left vertex is named 'object', the top vertex of the base 'definition', the right vertex - 'term', and the apex of the pyramid is named 'concept'.

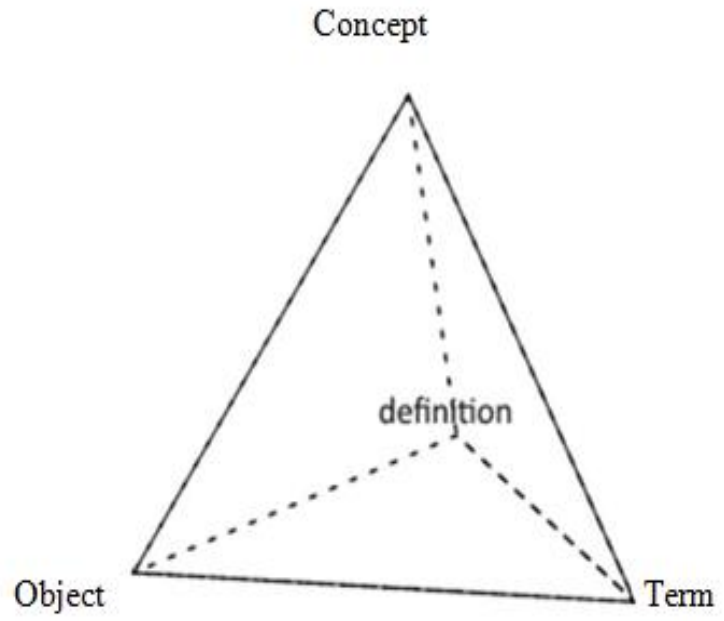

Fig. -4 A tetrahedron with definition as the fourth vertex (Kudashev, Kudasheva, 2010)

Putting the concept on the apex of the pyramid, at least geometrically demonstrates that linguistic signs and real-life phenomena (referent) are on one plain, but concept is not on the same plain with them. But again, it fails to demonstrate the process of communication because communication is "transmission and reception of information (a 'message') between a source and a receiver using a signaling system..." (Crystal, 2008 - 89).

But as it is seen, this tetrahedron does not take into consideration both the source and the receiver of linguistic signs and only describes the relationship between Object-Term-Definition-Concept. As communication requires encoding, transmission and decoding, its success depends on both sides: the source and the recipient.

The main function of human language is its communicative function and function is "a fundamental property of language itself". (Halliday, 1985 - 17). Thus, the process of communication requires a source of transmitted signs (speaker, writer) and a receiver of those signs (hearer, reader). What if on receiving the sign, the recipient gets wrong concept as in case with linguistic humor based on ambiguity? Thus, in this case, there is a problem either with the left vertex (sign) or the top vertex (concept) of the triangle. In the first case, the source of the information fails to send the right sign, in the second case, the receiver of the sign fails to decode it correctly. The first debatable question that arises here is whether information (meaning) is transmitted in the process of communication or only signs that represent it are transmitted? In other words, do the signs carry information (meaning)? If information is transmitted, then we must accept the idea of equality of information and sign. In that case, one and the same sign would never evoke different concepts in human mind in one and the same moment of discourse, and there would never be any ambiguity. But this is not the case. Information is based on concepts but only represented by the signs that stand for the referent.

Thus, only signs are transmitted, but not information. That is why each sign can mean different things to each person. The second question that arises here, is related to the top vertex (concept) of the triangle. Whom does the concept at the 
top vertex of the triangle belong to - the sender or the recipient? As we know, concepts do not exist independently from people's mind. They are in people's mind depending on their experience and are evoked on receiving relevant signs that symbolize them or are encoded with appropriate signs and transmitted.

But according to the triangle, as well as the above pyramid, that have one top vertex (concept), in case of ambiguity, one and the same sign that stands for the referent, can evoke different concepts in one mind simultaneously. Because two or more different interpretations cannot arise in one and the same mind simultaneously and the sender (speaker, writer) exactly knows what he means, neither the triangle nor the pyramid is able to demonstrate the process of communication. They only describe the process of correct decoding the received signs. Ambiguity arises in recipient's mind when he 'connects' the received sign to a wrong referent and thus gets a wrong concept and consequently, sometimes fails to interpret the speech correctly, i.e. exactly as the sender means. Then, the above geometrical shapes demonstrate the interpretation of the received signs not taking into consideration their origin or source. And thus, they describe the ideal, flawless decoding of received information.

As it was mentioned above, communication process requires the source and the recipient of the information. In the process of verbal communication, the actions done by the source (or the sender) of the information (speaker, writer) and by the recipient of the information (listener, reader) are quite opposite. The sender starts with the concept, then refers to the referent and from there 'goes' to the appropriate linguistic sign that stands for the referent - encodes the information choosing the relevant sign and sends the sign as in fig. 5

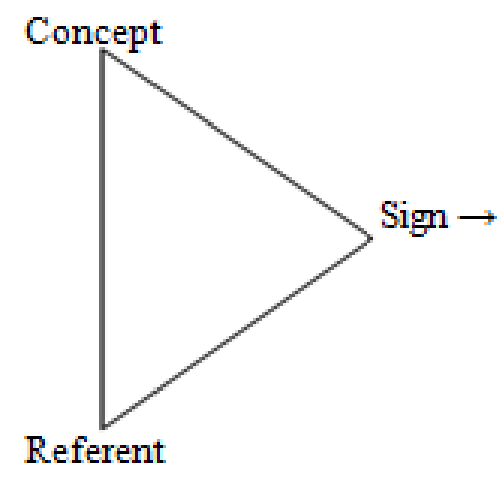

Fig. 5 - The sender's action in the process of communication

The recipient of the information acts in a reverse order: on getting the linguistic sign, he 'goes' from the sign to the relevant referent and from there to the concept. Thus, the completed communication act starts with the concept in the sender's mind and ends with the concept in the recipient's mind.

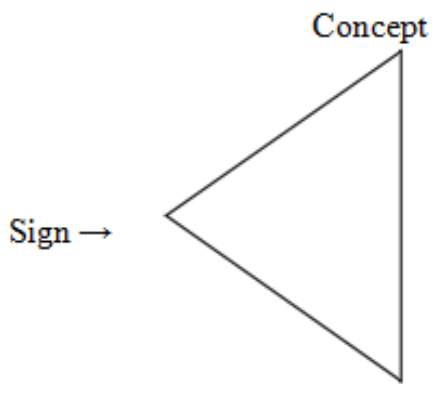

Referent

Fig. 6 - The recipient's action in the process of communication

Taking into consideration that linguistic signs are transferred in an ideal environment, i.e. excluding any obstacle that can prevent them from being sent and received (as the fig. 5 and fig. 6 demonstrate), there are five 'participants' that are involved in the process of communication viz linguistic sign (S) which is the same both for the sender and the 
recipient, the sender's concept (SC), the sender's referent (SR), the recipient's referent (RR) and the recipient's concept (RC). Successful communication takes place when these two concepts, i.e. SC and RC coincide. What happens in case of ambiguity? In that case, the sign sent by the sender is linked with the different referent than the one in the sender's mind, and thus a different concept evokes in the recipient's mind. What is common for both the sender and recipient is the linguistic sign and what is different are the referents and the concepts.

Then in case of ambiguity, one and the same linguistic sign (S) and two different referents, i.e. the sender's referent (SR) and the recipient's referent (RR) and two different concepts, i.e. the sender's concept (SC) and the recipient's concept $(\mathrm{RC})$ are involved in the process of communication which is geometrically represented below.

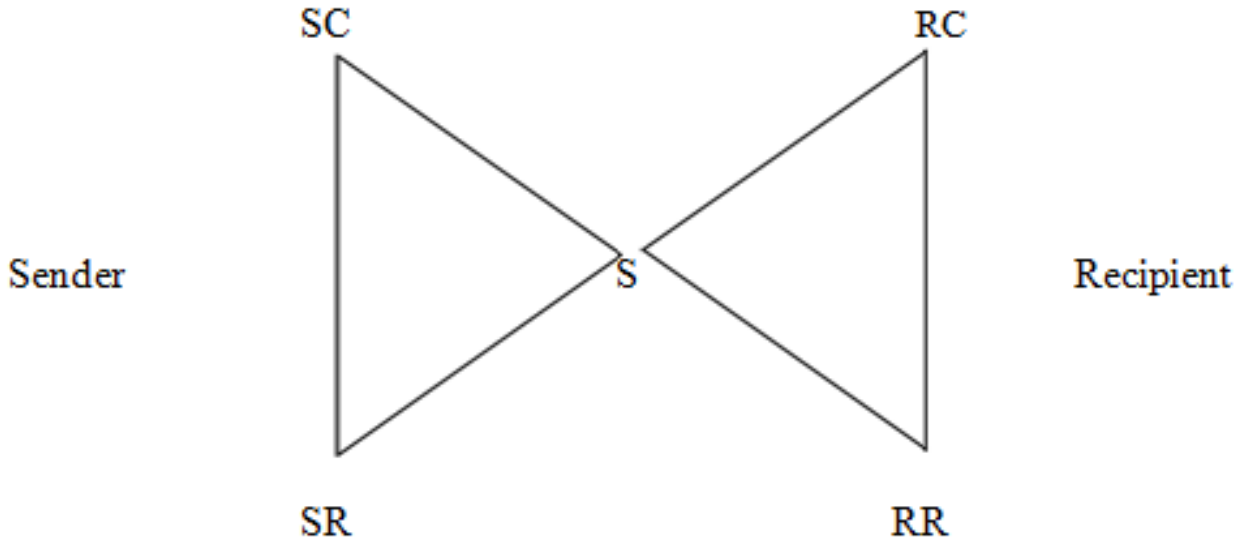

Fig. 7 - Communication-cognition 'butterfly' suggested by the author of this article

\section{Testing the communication-cognition 'butterfly'}

Linguistic humor based on ambiguity, is the best means to test and demonstrate how the communication-cognition 'butterfly' functions. Though some linguists claim that "we are aware that nearly everything we say has meaning on some level to ourselves as well as those we share our words with" (Bosco, 2002). Actually, it seems difficult to accept this stance that excludes ambiguity and misconception in human communication. Human communication is not flawless, and ambiguity is not a rare case. Linguistic ambiguity is defined as words, phrases or sentences that express more than one meaning. (Crystal, 2008, p.22), or a construction which admits more than one interpretation. In other words, in unintentional linguistic humor, the same linguistic sign evokes different concepts in the minds of the characters of the joke. Let us analyze some jokes:

\section{Joke 1 Next-door neighbor, to small boy: "Come again, Johnny. We'd like to see more of you."}

Johnny: "But there isn’t any more of me!" (Hoke, 1965, 82 - cited by Lew, 1996)

The misunderstanding of the small boy lies in the difference between the source concept and the recipient's concept. The sign 'to see more of you' chosen by the sender stands for the referent 'to see you again' and 'symbolizes the concept 'to see you again', whereas it is associated with the referent 'to see another you' and evokes the concept 'to see another you' in the recipient's mind. This happens due to lack of the appropriate referent (here: the prior linguistic experience) for the small boy and consequently, the relevant concept in his mind. 


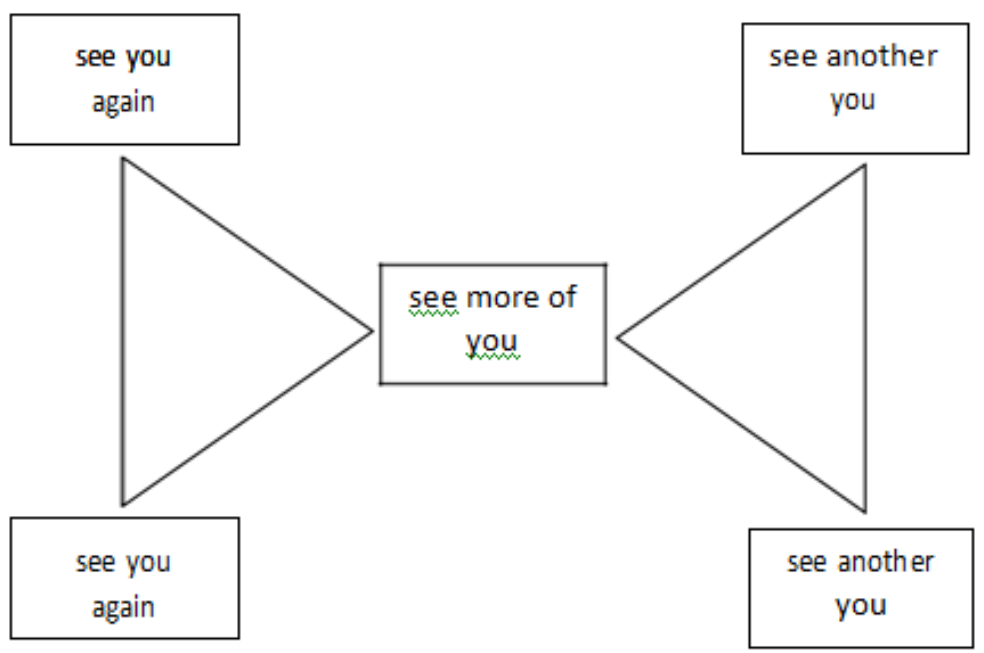

Fig. 8 - Demonstration of misconception in linguistic humor (Joke 1)

Joke 2 Judge, to a young girl: "Have you ever appeared as a witness in a suit before?"

\section{Girl: "Why of course!"}

Judge: "Will you please tell the jury what suit it was?"

Girl: "It was a pink suit, with collar and buttons all way down the front." (Miszdal, 1990, 786 - cited by Lew, 1996).

In this joke, the sign 'suit' stands for the referent 'court suit' and symbolizes the concept 'court suit' in the sender's mind, but it is linked with the referent 'outer garment' by the recipient and thus evokes the wrong concept in the recipient's mind. Thus, the gap in the young girl's prior linguistic experience is the source of her misunderstanding. One can argue that the girl's answer may be intentional in order to pretend not to understand what is asked. But as intentionality and unintentionality a different topic and remains out of scope of the present paper, we consider her irrelevant answer to be an unintentional one.

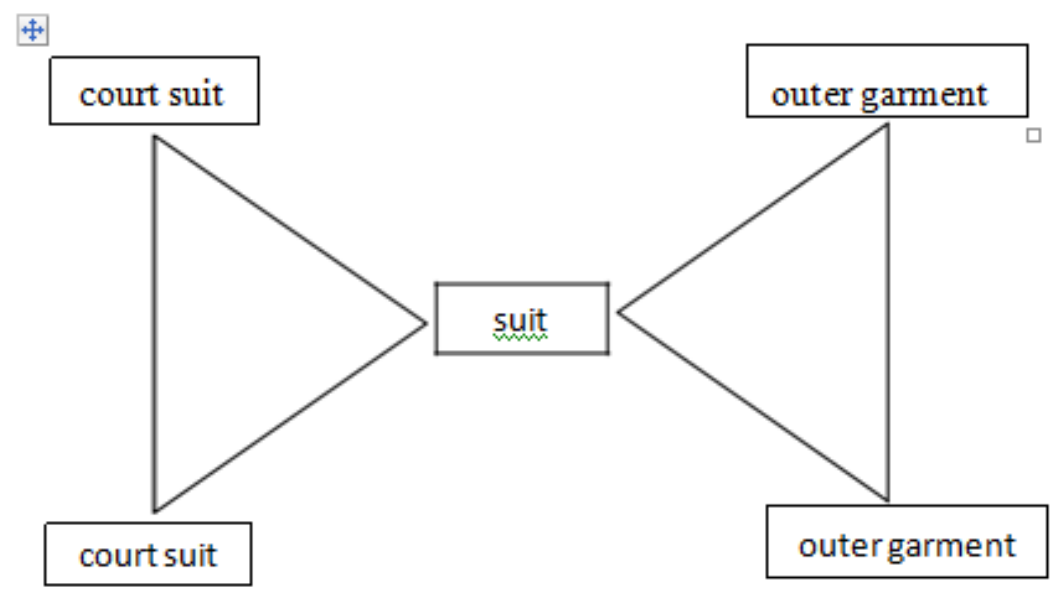

Fig. 9 - Demonstration of misconception in linguistic humor (Joke 2)

Joke 3 At small village station the booking clerk says to a villager who was unused to travelling: "You'll have to change twice before you get to York."

Villager says: "Goodness me! And I've only brought the clothes I be standing up in." (Potcheptsov 1974:159, cited - by Lew 1996) 


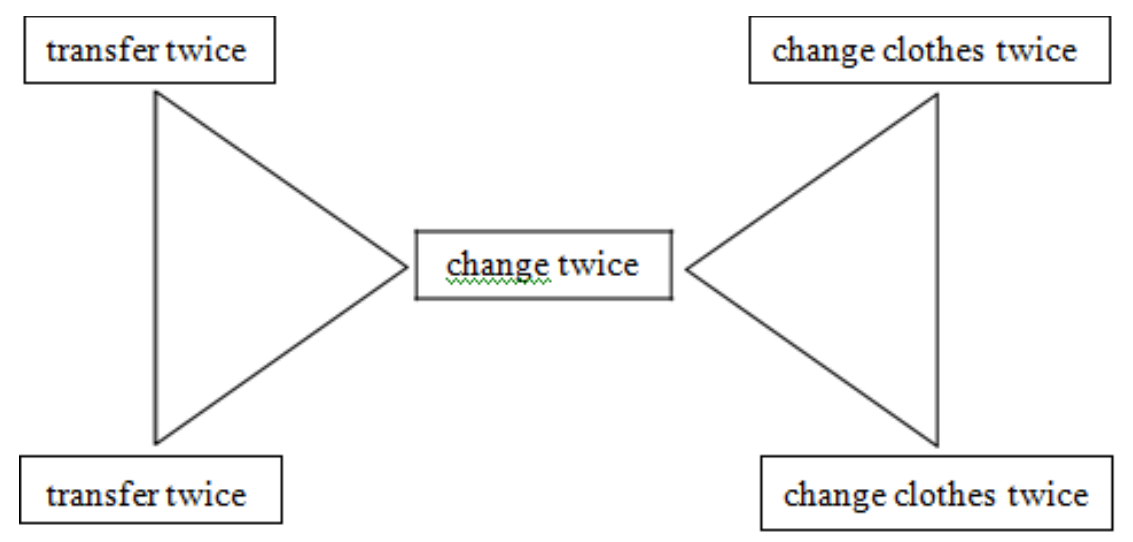

Fig. 10 - Demonstration of misconception in linguistic humor (Joke 3)

In this joke, the sign "to change" stands for the referent 'transfer' and symbolizes the concept "transfer" in the sender's mind, but it stands for the referent 'change clothes' and evokes the concept "change clothes" in the recipient's mind.

Thus, the analysis of the above jokes demonstrates that communication-cognition 'butterfly' can fully describe the process of communication the success of which depends on the extent of congruity between SC and RC. Moreover, it demonstrates that the number of concepts in human mind depends on peoples' language competence or language experience.

\section{Conclusions and further study}

Although the semantic triangle demonstrates the relationship between sign, referent and concept, and describes how the received or existing signs are decoded, it fails to demonstrate the process of human verbal communication which requires two parties - the sender and the recipient of linguistic signs. In order to demonstrate the communicationcognition process in case of linguistic ambiguity, not one but two triangles are needed, viz the sender's triangle where linguistic signs are encoded and sent and the recipient's triangle where the received linguistic signs are decoded. The communication-cognition 'butterfly' suggested in this paper where alongside with arbitrary linguistic signs, both the source (sender's) referent and concept and the recipient's referent and concept are represented, can serve this purpose.

The completed communication act starts with the concept in the sender's mind and ends with the concept in the recipient's mind. It means, that human communication takes place between two minds indirectly, i.e. through arbitrary linguistic signs that evoke concept or meaning in people's minds. Then, meaning is something subjective rather than objective and cannot exist beyond people's minds. Successful communication is transmission of concepts between the source and the receiver. Had we been able to communicate telepathically, we would not have had the need of arbitrary linguistic signs and there would never had been any ambiguity in human communication. Linguistic signs are not ambiguous per se, as they do not carry meaning; meaning or concept is evoked in people's minds upon receiving linguistic signs and depends on their 'knowing' of the world and linguistic experience. This subjective way of interpretation induces the difference between the source concept and the recipient's concept and this very difference induces ambiguity in human language.

Not claiming for the last word in this question, we consider that further investigation in this direction can shed light on the problem under consideration and be useful in modelling human communication.

\section{References}

Bosco, A. (2002). What do you Mean: A Brief Look at Ogden and Richards' Theory of Meaning. Crystal, D., (2008). A Dictionary of Linguistics and Phonetics. 6th Edition. Oxford: Blackwell Publishing

Finegan E. (2008). Language: It's Structure and Use. Fifth Edition. Thomson Higher Education, Boston, USA

Halliday, M.A.K. 1985. Language, context and text: Aspects of language as social semiotic. Geelong: Deakin University Press. Chapter 2. p. 17

Halliday, 1985. "Systemic Background". In Systemic Perspectives on Discourse, Vol. 1: Selected Theoretical Papers from the Ninth International Systemic Workshop, Benson and Greaves (eds). Vol. 3 in The Collected Works, p. 193. 
Kudashev Igor, Irina Kudasheva. (2010). Semiotic Triangle Revisited for the Purposes of Ontology-based Terminology Management.

Lew R., (1996). An Ambiguity-based Theory of the Linguistic Verbal Jokes in English.

Doctor's Thesis, Adam Mickiewicz University.

Martin Haspelmath. The geometry of grammatical meaning: Semantic maps and cross-linguistic comparison. The new psychology of language, vol. II, Mahwah, NJ, May 2000) Ogden, C.K. and Richards, I.A. (1923). The Meaning of Meaning. A study of the influence of language upon thought and of the science of symbolism. London: Routledge and Kegan Paul.

Sue Ellen Wright. Standards for the Language Industry. Terminology, Computing and Translation (Google Books) 